\title{
Developing Dental Faculty for the Future: ADEA/AAL Institute for Teaching and Learning, 2006-09
}

\author{
N. Karl Haden, Ph.D.; William D. Hendricson, M.A., M.S.; John W. Killip, D.D.S.; \\ Paula N. O'Neill, M.Ed., Ed.D.; Michael J. Reed, B.D.S., Ph.D.; George Weinstein, M.B.A.; \\ John N. Williams, D.M.D., M.B.A.; Richard W. Valachovic, D.M.D., M.P.H. \\ Abstract: This report summarizes the history and curriculum of the American Dental Education Association/Academy for \\ Academic Leadership Institute for Teaching and Learning (ADEA/AAL ITL) Program for Dental School Faculty, describes \\ participant feedback, and reviews how the program serves the faculty development initiatives of the American Dental Education \\ Association. The fifty-hour program (6.5 days), conducted in two phases at collaborating dental schools, enhances core academic \\ competencies of new and transitional faculty, including faculty members whose responsibilities include predoctoral, allied, and \\ postdoctoral dental education. The program's mission is to prepare participants to become more effective teachers and develop \\ other skills that will facilitate confidence, job satisfaction, and professional growth in the academic environment. From 2005 to \\ 2009, 174 individuals graduated from the program, representing forty-three schools of dentistry in the United States and Canada \\ and twenty-nine private practices. A total of forty scholarships have been awarded to participants by the American Academy of \\ Periodontology Foundation, the American Academy of Pediatric Dentistry, and the American Association of Orthodontists. In \\ an online survey completed by 75 percent of ADEA/AAL ITL participants, 99 percent indicated they were positive or highly \\ positive about their learning experience in this faculty development program. Ninety-six percent stated that the program had been \\ important or very important in their effectiveness as a teacher. In 2010, the program will be held at the University of North Caro- \\ lina at Chapel Hill School of Dentistry, with phase I occurring on August 19-22, 2010, and phase II on October 22-24, 2010. In \\ summary, the ADEA/AAL ITL is addressing an unmet need through a formal professional development program designed to help \\ new and potential faculty members thrive as educators and become future leaders in academic health care.
}

Dr. Haden is President, Academy for Academic Leadership; Prof. Hendricson is Director of Education, Academy for Academic Leadership, and Assistant Dean, Educational and Faculty Development, University of Texas Health Science Center at San Antonio Dental School; Dr. Killip is Clinical Associate Professor and Assistant Dean for Student Programs, University of Missouri-Kansas City School of Dentistry; Dr. O’Neill is Professor of Diagnostic Sciences and Associate Dean for Educational Research and Professional Development, University of Texas Health Science Center at Houston Dental Branch, and Senior Consultant, Academy for Academic Leadership; Dr. Reed is Dean Emeritus, University of Missouri-Kansas City School of Dentistry; Mr. Weinstein is Program Manager, Academy for Academic Leadership; Dr. Williams is Dean, University of North Carolina at Chapel Hill School of Dentistry; and Dr. Valachovic is Executive Director, American Dental Education Association. Direct correspondence and requests for reprints to Dr. N. Karl Haden, Academy for Academic Leadership, 1870 The Exchange, Suite 100, Atlanta, GA 30339; 404-350-2098; khaden@academicleaders.org.

Proprietary Interest Disclosure: The Academy for Academic Leadership has a fiscal interest in the faculty development program described in this article.

Keywords: dental education, faculty development, Academy for Academic Leadership, American Dental Education Association, teaching, learning

$\mathrm{O}$ ver half of the new faculty coming into dental schools were from private practice, and more than 400 budgeted faculty vacancies existed in 2006-07 according to the most recent American Dental Education Association (ADEA) survey of dental faculty workforce issues. ${ }^{1}$ Consequently, there is a need to give new educators the tools to thrive in the challenging environment of academic dentistry.
The ADEA/AAL [Academy for Academic Leadership] Institute for Teaching and Learning (ITL) is a professional development program designed to prepare dentists and dental educators for successful academic careers. The program goal is to help participants, designated as ADEA/AAL ITL Scholars, refine teaching skills that will enhance the quality of their interactions with today's students and develop 
other skills to facilitate confidence, job satisfaction, and professional growth in the academic environment. The fifty-hour curriculum is conducted onsite at a collaborating dental school in two phases that are separated by approximately two months. Scholars complete between-phase "translational" assignments at their home institutions and through online learning to allow application of key concepts introduced in the program.

Its goals cover five areas:

1. Faculty Recruitment. As a component of ADEA's campaign to promote academic dental careers, ADEA/AAL ITL provides a mechanism to identify potential faculty from advanced dental education programs, private practice, and other sources, which will assist ADEA academic dental institutions in the development of faculty to implement academic programs and sustain institutional vitality.

2. Development of Academic Skills. The program enhances the professional development of allied, dental, and advanced dental faculty members who are transitioning into the dental school environment from nonacademic settings and those who are new to academic dentistry so that they gain competence in the theory and practice of teaching and learning and become familiar with the policies, procedures, processes, and career opportunities within the academic environment.

3. Career Planning. The ADEA/AAL ITL assists in the retention of new faculty at ADEA academic dental institutions through the development of scholarship in teaching and learning and by facilitating career planning so that these faculty members can succeed in academia and thereby improve the quality of their work-life.

4. Pipeline to ADEA Society of Teaching and Learning (SoTL). The program creates a pipeline of predoctoral, allied, and advanced dental educators who will continue their professional development and their contributions to dental education through membership in ADEA and participation in ADEA's SoTL. In time, the network of alumni should contribute to the professional development and mentoring of other faculty as they progress through their academic careers.

5. Institutional Enhancement. The $\mathrm{ADEA} / \mathrm{AAL}$ ITL provides new faculty members who participate in the program with the knowledge and tools to return to their home institutions and teach other faculty members about relevant topics in the scholarship of teaching and learning and innovations in curricula.

In this report, we will review faculty development strategies and assessment of their effectiveness within the broader environment of health professions education and then focus on current faculty workforce issues in dental education. The ADEA/AAL Institute for Teaching and Learning will be described within the context of ADEA's spectrum of activities to attract and retain faculty members and optimize their educational practice. The design and content of the program will be described, and findings from participants' evaluation will be presented.

\section{What Is Faculty Development, and How Is It Accomplished?}

In one of the seminal works on faculty development for health professions education, Wilkerson and Irby wrote that "academic vitality is dependent upon faculty members' interest and expertise; faculty development has a critical role to play in promoting academic excellence and innovation and it is a tool for improving the educational vitality of our institutions through attention to the competencies needed by individual teachers and to the institutional policies required to promote academic excellence."² Bland, a leading faculty development authority in medical education, and her colleagues have described faculty development as a "planned program to prepare institutions and faculty members for their academic roles including teaching, research, administration, scholarship, and career management." Within the environment of academic dentistry, O'Neill and Taylor have observed that extensive faculty development programs characterize the culture of dental schools that value teaching and that "faculty development is needed at all levels of faculty life, from novice instructor through the administrator, to address the various levels in the educational enterprise."

A hierarchy of faculty development strategies to enhance the teaching effectiveness of faculty has been described by Ullian and Stritter. ${ }^{5}$ This hierarchy comprises a continuum of developmental activity: 1) individual, self-directed activities such as reading, reflection, and self-assessment, watching (in person or by videotape) other teachers "in action" and noting techniques, and appraisal of teaching effectiveness evaluations provided by students; 2) 
shadowing experienced teachers; 3) being videotaped while teaching and then critiquing, personally or with assistance from a consultant or faculty peer; 4) participating in lectures, journal clubs, or "lunchand-learns" that expose faculty members to literature and research on educational issues; 5) participating in brief workshops (three to six hours) focusing on teaching competencies such as providing feedback, asking questions to promote critical thinking, or constructing examinations; 6) participation in teaching enhancement courses of several days' duration, often called "immersion" programs; and 7) organizational strategies to promote, assess, and reward teaching effectiveness including mentoring programs for junior faculty and tuition support for faculty to participate in academic leadership fellowships.

The most comprehensive review of the effectiveness of faculty development to enhance teaching was published by the Best Evidence in Medical Education Collaborative (BEME) in the June 2006 issue of Medical Teacher. ${ }^{6}$ The BEME is an international organization of health professions educators who share a mission to move the education of care providers from "opinion-based education to evidence-based education." The BEME has produced more than twenty systematic reviews of the evidence related to various aspects of health professions education. The BEME's review of the outcomes of faculty development considered all forms of teaching enhancement strategies described by Ullian and Stritter. ${ }^{5}$ The BEME reviewed fifty-three studies of faculty development effectiveness in health professions education that met their research methodology criteria, out of an original sample of 303 papers, and reported these conclusions:

- Participant satisfaction with faculty development programs on teaching effectiveness was high. Programs with a practical and skills-based focus were the most valued.

- Participants reported a positive change in attitudes toward teaching enhancement as a result of their involvement.

- Participants reported and/or demonstrated increased knowledge of educational concepts and specific techniques such as assessing learners' needs, promoting reflection, and providing feedback.

- Self-perceived changes in teaching behavior were consistently reported.

- Participants reported greater involvement in educational development and establishing new networks of colleagues. ${ }^{6,7}$
Overall, the BEME study and other reviews of the faculty development literature ${ }^{2,3,6-10}$ concluded that effective faculty development programs have these characteristics: several days in duration and conducted away from the academic workplace to provide a distraction-free environment (i.e., immersion format); hands-on learning through skill practice sessions; the opportunity for participants to provide each other with feedback; an emphasis on self-assessment; the opportunity for participant networking; and the opportunity for participants to apply new skills at their home institution in translational activities. Of pertinence to academic dentistry, there have been only three recent reports of the outcomes of faculty development initiatives in dental schools. ${ }^{11-13}$

\section{Faculty Development in Dental Education}

Development of the academic skills of the faculty has become a critical component of health professions education, which for decades adhered to the tradition that competence in the biological and clinical sciences naturally morphed into competence in classrooms, laboratories, and clinics. However, it is now recognized that preparing health professions faculty for teaching responsibilities is a necessary function of academic institutions.

Professional development is critically important in dental education in 2009. As has been widely discussed, academic dentistry is graying and struggles to attract younger dentists into the educational arm of the profession. Fifty percent of dental school deans recently reported that faculty recruitment and retention were significant problems, and more than half indicated that filling vacant positions will be more difficult in the future. ${ }^{1}$ In the past decade, more than 10 percent of the faculty workforce left dental education annually, primarily for private dental practice or retirement. Faculty less than forty-five years of age are the most likely to depart for private practice. ${ }^{1}$ The loss of substantial numbers of junior faculty members is a major workforce concern because the strength of educational programs rests on teachers and researchers who plan lifelong academic careers and thus have the longevity to acquire the competencies, experience, and academic credentials to become valuable contributors to the overall mission of the parent institution. ${ }^{14}$ Since 2000 , faculty leaving dental education have been replaced by equivalent numbers 
of individuals from two sources: those who were hired away from other dental schools, thus providing no net gain for dental education overall, merely a shifting of resources; and those who are completely new to academia. Most of the true new recruits to academic dentistry are in the fifty-five to sixty-five age range and are ending their private practice or military dentistry careers. In most cases, the older, "second career" recruits into dental education have little knowledge of contemporary educational theory and teaching practices and have limited experience with the culture, decision making processes, and scholarship expectations of the academic environment. ${ }^{7,15}$

Within this context, the Academy for Academic Leadership created the ITL program to assist dental education in the recruitment, development, and retention of faculty. The principal coordinators of the initiative are Dr. N. Karl Haden, AAL president, Prof. William Hendricson, AAL director of educational programming, and AAL senior consultant Dr. Paula O'Neill. The program has been conducted onsite at two collaborating partner dental schools: the University of Missouri-Kansas City School of Dentistry and the University of North Carolina at Chapel Hill School of Dentistry. Since its inception in 2005, AAL has trained over 400 dental and allied dental faculty and private practitioners in several different professional development programs that address contemporary teaching and learning strategies, career planning, and academic management. Of this number, 174 have completed the ITL program.

The ADEA/AAL ITL addresses a central aspect of ADEA's faculty development continuum as depicted in Figure 1. ADEA provides a spectrum of support and enrichment opportunities that reflects the career arc of dental school faculty and consists of four components: 1) the Academic Dental Careers Fellowship Program (ADCFP) to promote and support interest in academic careers among students; 2) the Society of Teaching and Learning (SoTL) community to provide enrichment and networking opportunities for a broad segment of the ADEA membership in conjunction with faculty development workshops at the ADEA Annual Session; 3) the Institute for Teaching and Learning, which provides an in-depth learning experience for early career faculty members or practitioners transitioning into the academic environment; and 4) the ADEA Leadership Institute for mid-career faculty members who desire to attain program leadership roles or enhance their effectiveness in these roles.

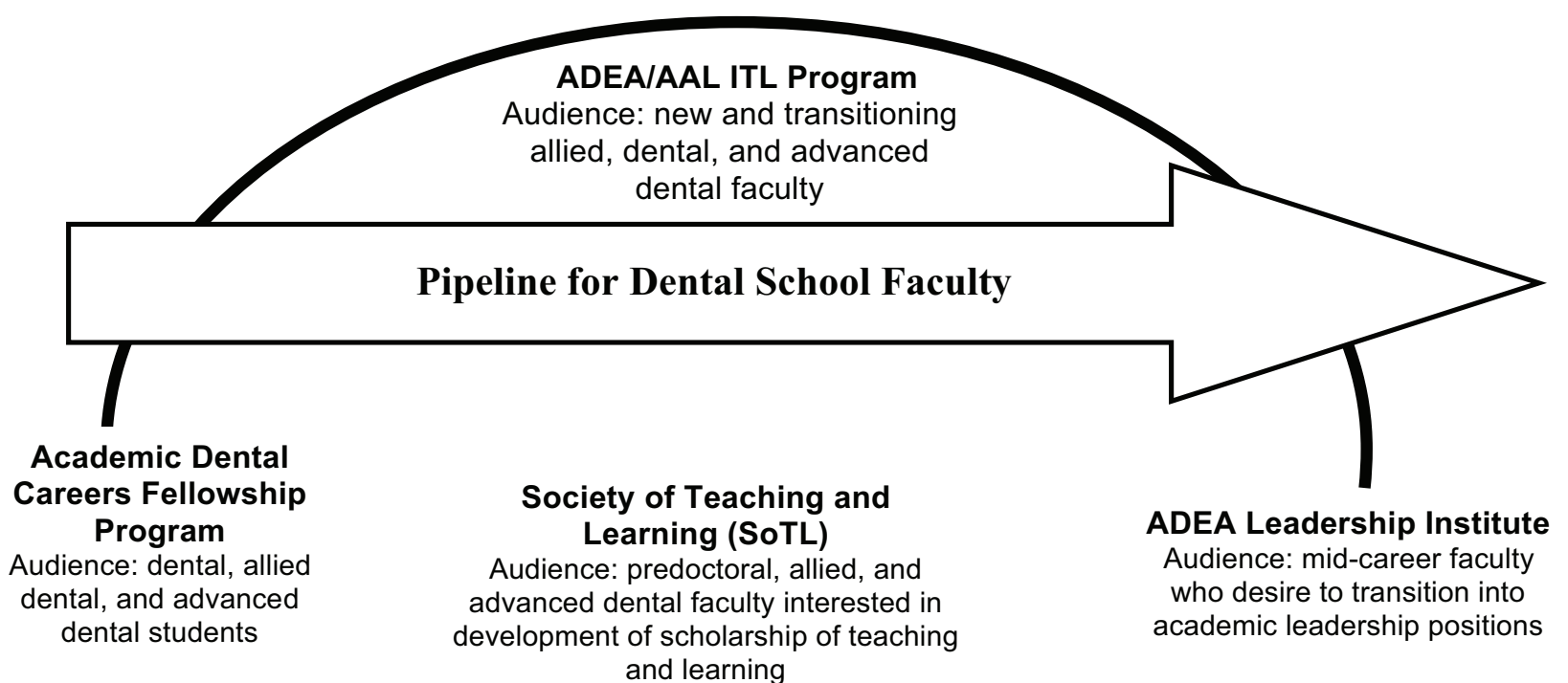

Figure 1. ADEA faculty development continuum 


\section{The ADEA/AAL Institute for Teaching and Learning}

In the ADEA/AAL ITL, cohort groups of twenty-five to forty participants from a variety of dental schools and the practice community complete a 6.5-day program, conducted in two phases (phase one is 3.5 days, and phase two is three days), that addresses skills in teaching, curriculum planning, student assessment, educational principles, student characteristics, academic culture, and career planning. Scholars experience a variety of learning activities including "at-home" application assignments between phases, team projects, teaching simulations involving role-play, peer feedback, critiques of other teachers "in action" (observed on videotape), and analysis of case scenarios depicting teacher-student interactions. The design of the program is based on best practice evidence from the faculty development literature. The BEME report previously described and other reviews of this literature indicate that longitudinal immersion programs emphasizing active learning such as incorporated into the ADEA/AAL ITL are the most likely to produce modifications in attitudes and incorporation of newly acquired skills into routine teaching practices. ${ }^{2,6,7,16}$

\section{Curriculum}

The objectives of the program and curriculum topics were initially identified in 2005 and 2006 by administration of AAL's Professional Needs Assessment (PNA) survey to groups of faculty at several dental schools. The online PNA asked respondents to indicate their need for additional training for a variety of academic skills in the following areas: teaching and learning concepts and strategies, instructional design and curriculum planning, student assessment, scholarship, academic administration, and career planning. Prior to each administration of the ADEA/ AAL ITL and other AAL faculty development programs with similar objectives, participants complete the PNA to help program faculty identify topics of particular interest. Thus, the curriculum changes to some extent from year to year based on participants' perceptions of need, although fundamental skills such as techniques for assessing students' competence are emphasized in each session. The curriculum is also based on the findings and recommendations of a number of studies of the characteristics of effective teachers in health professions education ${ }^{17-21}$ and the outcomes of Hand's study of essential core competencies for dental school faculty. ${ }^{22}$

During the program, ADEA/AAL ITL Scholars receive hands-on experience with key teacher tasks such as evaluating student competence, planning and presenting lectures, planning courses, constructing tests in several formats including new assessment strategies such as the triple jump exercise and portfolios, ${ }^{23}$ small-group learning, working with struggling and challenging students, promoting students' critical thinking, and providing feedback. Participants also explore cognitive theories, review research on educational best practices, explore dental students' learning style preferences, assess their own personality profile and consider the implications for interaction with peers and students, analyze the characteristics of today's Gen Y learner, complete teaching self-assessments, and participate in simulations to evaluate dental students' performance. The program includes sessions on developing a career plan, preparing CVs, and chairing committees. Participants also participate in a "Buns and Brains" debate (conducted during a breakfast session), at which they analyze and debate an issue in dental education. Scholars provide an inservice education at their home institution related to one of the topics addressed in the program and tour the facilities of the collaborating dental school. The 2009 core curriculum appears in Figure 2. Specific learning objectives for each topic can be reviewed at www.academicleaders.org/itl.html. ADEA/AAL ITL Scholars receive fifty hours of CERP continuing education credit, a framed program completion certificate, and a letter of recognition that is sent to the dean of their dental school.

\section{History}

Following a 2005 pilot implementation at the University of Nevada, Las Vegas (UNLV) School of Dental Medicine, AAL launched the ITL program in 2006 at the University of Missouri-Kansas City (UMKC) School of Dentistry with twenty-four participants from thirteen dental schools and five private practitioners who were either in the process of transitioning to academic careers or exploring this career change. The American Academy of Periodontology Foundation (AAPF) provided six scholarships for 2006 ITL Scholars.

In December 2006, ADEA issued a request for proposals for an Academic Competencies Enhancement Program to address the teaching and learning needs of new faculty and the dental practitioner 
- Academic career planning, including transitioning from private practice into academia

- Assessment of students' progress toward competence

- Buns and Brains debate of dental education issues

- Case-based learning

- Chairing committees and conducting effective meetings

- Clinical teaching best practices

- Classroom teaching best practices

- Course planning and instruction design

- Critical thinking

- Dental education issues, controversies, and future directions

- In-service education "teach-back" at home institution

- Learning environment, including sources of stress and concern for students

- Personality and learning styles, including working with the Gen Y "Millennial" student

- Principles of learning and cognitive factors that influence learning

- Working productively with struggling and challenging students

Figure 2. Curriculum topics of the ADEA/AAL Institute for Teaching and Learning

seeking transitional support for movement into the academic culture. As a result of its response to the proposal request, AAL became a collaborating partner with ADEA to provide the ITL and an associated program known as the Institute for Allied Health Educators (IAHE), which has similar objectives and content but focuses on issues germane to allied health educators. The IAHE has been conducted annually since 2007 in conjunction with a collaborating dental school partner, the University of Missouri-Kansas City.

From 2006 to 2009, the ADEA/AAL ITL was conducted six times at either the UMKC or UNC$\mathrm{CH}$ Schools of Dentistry with a total attendance of 174. The AAPF has awarded a total of twenty-two scholarships to support participation; the American Academy of Pediatric Dentistry has awarded ten scholarships; and the American Association of Orthodontists has provided eight scholarships.

\section{Participants' Evaluation}

In December 2008, AAL conducted an outcomes evaluation of the program with three objectives:

1. Develop a profile of ADEA/AAL ITL Scholars;
2. Determine participants' perceptions of the benefits and overall value of the program; and

3. Identify areas for improvement.

\section{Methodology of Assessment}

The overall long-term outcomes assessment for the ADEA/AAL ITL is based on Kirkpatrick's multidimensional model of training evaluation, which includes measurement at four levels: 1) participants' satisfaction with training experiences and their attitudes toward the topic; 2) participants' perception and self-report of knowledge and skill acquisition; 3) behavioral change in participants (demonstrated capacity to use knowledge and skills to solve problems); and 4) institutional outcomes (retention of participants in positions, longitudinal career tracking, and institutional satisfaction with products of training). ${ }^{24}$ The methodology and findings reported here pertain to assessment levels one and two, which are typically obtained by questionnaire.

The questionnaire created for the outcomes assessment utilized an online format based on a template available from SurveyMonkey.com. It employed a combination of response formats: forced choice from a menu, multiple allowable answers, and open-ended written comments. The questionnaire was reviewed and piloted by program instructors; 
feedback from this group was incorporated into the final version of the instrument. In the first section of the questionnaire, respondents answered fifteen questions to build a profile of ADEA/AAL ITL Scholars, including demographics, academic degrees, primary discipline, year of participation, scholarship support, and academic rank in the year they attended the program. Part two contained fifteen questions that assessed specific aspects of the curriculum and its impact on the participants' abilities in the classroom and clinical setting. Additional questions focused on an overall assessment of the program, its importance in making the participant a more effective teacher, its presentation of a realistic preview of academic health care to private practitioners, and influence on participation in ADEA. The third section asked the respondents to describe the most and least valuable experiences during the program, identify areas where they desired further training and experience as teachers, and provide suggestions for improvements.

\section{Distribution of ADEA/AAL ITL Scholars Follow-Up Evaluation}

The questionnaire was supplied electronically in December 2008 to 102 Scholars who graduated from the 2006, 2007, and 2008 programs. AAL sent an email message that informed them of the objectives of the survey, the due date for responses, and the intended usage of the data by AAL and ADEA. The instructions noted that providing names was optional and that, regardless of whether respondents identified themselves, no individuals would be identified in any subsequent publications or presentations and no answer would be directly attributed to a specific individual. AAL requested all recipients to respond

Table 1. Gender and ethnicity of survey respondents, by percentage of total respondents $(\mathrm{N}=102)$

\begin{tabular}{lc} 
Gender/Ethnicity & Percentage \\
\hline Male & $70 \%$ \\
Female & $30 \%$ \\
& \\
White/Caucasian & $78 \%$ \\
African American & $9 \%$ \\
Asian American/Pacific Islander & $8 \%$ \\
Hispanic & $3 \%$ \\
Other & $3 \%$
\end{tabular}

Note: Ethnicity percentages do not total $100 \%$ because of rounding. within one month. A reminder was sent midway through this period.

\section{Results}

A total of seventy-six ADEA/AAL ITL Scholars responded to the survey. This constituted a response rate of 75 percent from the 2006-08 cohort $(\mathrm{N}=102)$. (Participants in the 2009 program have not yet completed the evaluation, so could not be included.) Seventy percent of the respondents were male - though, in the total cohort, males constituted only 60 percent of the total; the large majority of both males and females identified themselves as Caucasian (Table 1). The average age of all respondents in the year they graduated from the program was forty-seven years, the median age was forty-nine, and, while the population of those replying was multi-modal, the largest modes were thirty-one and fifty-five years of age (Table 2).

Table 3 shows the response rate from each class of ADEA/AAL ITL Scholars. The Class of 2008 comprised the largest number of participants in the survey, with thirty-eight of the seventy-five responses and, incidentally, boasted the largest graduating class (fifty). Three-quarters of both the 2006 class and 2008 class responded to the questionnaire. The 2007 class consisted of thirty-seven Scholars, twenty-two of whom responded to the survey.

The next two questions in the survey gathered data about the relative teaching experience of the full- and part-time faculty members who participated in the program. Since the program is targeted to those new to academia, it came as no surprise that a significant portion of the faculty responding to the questionnaire had taught for only five years or less as shown in Table 4. Sixty-five percent of respondents were assistant professors during the program, and

Table 2. Age of survey respondents, by percentage of total respondents $(\mathrm{N}=102)$

\begin{tabular}{lc} 
Age Range & Percentage \\
\hline $20-29$ years & $4 \%$ \\
$30-39$ & $31 \%$ \\
$40-49$ & $20 \%$ \\
$50-59$ & $31 \%$ \\
$60-69$ & $13 \%$ \\
70 and older & $2 \%$
\end{tabular}

Note: Percentages do not total $100 \%$ because of rounding. 
Table 3. Year of graduation from the program, by percentage of class responding and percentage of total respondents

\begin{tabular}{ccc} 
Year & $\begin{array}{c}\% \text { of } \\
\text { Class Responding }\end{array}$ & $\begin{array}{c}\% \text { of } \\
\text { Total Respondents }\end{array}$ \\
\hline 2006 & $75 \%$ & $20 \%$ \\
2007 & $59 \%$ & $29 \%$ \\
2008 & $75 \%$ & $51 \%$
\end{tabular}

15 percent indicated they were in private practice (Table 5).

To assess perceptions of program design, respondents were asked to indicate their level of agreement with fifteen statements describing program characteristics and qualities. More than 80 percent of respondents agreed or strongly agreed with each statement (Table 6). Notably, 81 percent of ADEA/ AAL ITL Scholars indicated that they had discussed the program with colleagues, 89 percent indicated that it had been helpful in career planning, and 89 percent indicated that it helped them become a more effective contributor to their department. Eighty-nine percent indicated that the program "enhanced my confidence that I can be successful in an academic career." All respondents agreed that it "stimulated me to think about the environment for teaching and learning in clinics and to consider potential modifications," and 100 percent also agreed that it "provided me with a broader perspective on how students learn and factors that may hinder learning." Ninety-eight percent of the respondents indicated that they "learned new perspectives that will help me understand students and what drives their behaviors and attitudes."

The next question requested an overall assessment of the ADEA/AAL ITL program. As shown in Table 7, 99 percent of respondents rated their experience as positive or highly positive. In addition, 89 percent of the respondents indicated that the program was "important" or "very important" to their development as effective teachers, and 99 percent indicated that they would recommend the program to a colleague. Scholars who were not engaged in academia at the time of the program were asked if it helped them decide whether to pursue a faculty position; 83 percent of respondents found the program to be helpful in this regard.

Respondents were also asked to indicate their affiliation with ADEA and level of participation in ADEA. The data displayed in Table 8 demonstrate that while the majority of respondents are members
Table 4. Number of years ADEA/AAL ITL Scholars have taught full- or part-time, by percentage of total respondents

\begin{tabular}{lc} 
Full-Time Faculty & Percentage \\
\hline Less than 1 year & $7 \%$ \\
$1-5$ years & $71 \%$ \\
$6-9$ years & $14 \%$ \\
10 or more years & $7 \%$
\end{tabular}

Part-Time Faculty Percentage

Less than 1 year 0

$1-5$ years $16 \%$

$6-9$ years $\quad 5 \%$

10 or more years $\quad 8 \%$

Not applicable $\quad 71 \%$

Note: Full-time faculty percentages do not total $100 \%$ because of rounding.

Table 5. Academic rank at the time of program attendance, by percentage of total respondents

\begin{tabular}{lc} 
Academic Rank & Percentage \\
\hline Assistant professor & $65 \%$ \\
Associate professor & $9 \%$ \\
Instructor & $6 \%$ \\
Professor & $3 \%$ \\
Other & $3 \%$ \\
Not applicable; in private practice & $15 \%$ \\
Note: Percentages do not total $100 \%$ because of rounding.
\end{tabular}

of ADEA, only a third of them had participated in an ADEA activity in the past twelve months. This presents an opportunity for ADEA to engage a number of highly motivated teachers and potential academic leaders.

ADEA/AAL ITL Scholars were also asked to indicate the nature of their participation in ADEA. Twenty-four respondents indicated they had been involved in one of more of the activities below, with attendance at the ADEA Annual Session $(n=17 / 24)$ representing the most frequent activity:

- attended the ADEA Annual Session,

- participated in the peer review process for the Journal of Dental Education,

- leadership positions within ADEA Sections, and/ or

- participated in the ADEA Leadership Institute.

The third section of the questionnaire consisted of open-ended questions designed to solicit ADEA/ AAL ITL Scholars' perceptions of the most valuable 
Table 6. Perceptions of the ADEA/AAL ITL by 2006-08 participants, by percentage of total respondents

\begin{tabular}{|c|c|c|c|c|c|}
\hline & $\begin{array}{l}\text { Not } \\
\text { Applicable }\end{array}$ & $\begin{array}{l}\text { Strongly } \\
\text { Disagree }\end{array}$ & Disagree & Agree & $\begin{array}{l}\text { Strongly } \\
\text { Agree }\end{array}$ \\
\hline $\begin{array}{l}\text { I was exposed to new ideas, concepts, and methods that } \\
\text { will help me in my classroom teaching. }\end{array}$ & $5 \%$ & & $1 \%$ & $30 \%$ & $65 \%$ \\
\hline $\begin{array}{l}\text { The laminated "Clinical Teaching Tips" cards are a useful } \\
\text { resource. }\end{array}$ & $11 \%$ & $3 \%$ & $3 \%$ & $40 \%$ & $44 \%$ \\
\hline $\begin{array}{l}\text { ITL enhanced my confidence that I can be successful in an } \\
\text { academic career. }\end{array}$ & $3 \%$ & $1 \%$ & $8 \%$ & $32 \%$ & $57 \%$ \\
\hline $\begin{array}{l}\text { I was exposed to new ideas, concepts, and methods that will } \\
\text { help me in my clinical teaching. }\end{array}$ & $5 \%$ & $1 \%$ & $1 \%$ & $29 \%$ & $63 \%$ \\
\hline $\begin{array}{l}\text { The opportunity to exchange ideas and philosophies about } \\
\text { teaching with my colleagues was beneficial. }\end{array}$ & $3 \%$ & & $1 \%$ & $21 \%$ & $74 \%$ \\
\hline $\begin{array}{l}\text { ITL stimulated me to reflect on my role as a teacher and about } \\
\text { my philosophy of teaching. }\end{array}$ & $5 \%$ & & & $22 \%$ & $72 \%$ \\
\hline $\begin{array}{l}\text { I learned new perspectives that will help me understand } \\
\text { students and what drives their behaviors and attitudes. }\end{array}$ & $1 \%$ & & & $22 \%$ & $76 \%$ \\
\hline $\begin{array}{l}\text { ITL helped me explore how my personality, values, and } \\
\text { preferences influence my interaction with students. }\end{array}$ & $3 \%$ & & $1 \%$ & $32 \%$ & $64 \%$ \\
\hline $\begin{array}{l}\text { ITL stimulated me to think about the environment for teaching } \\
\text { and learning in clinics and consider modifications. }\end{array}$ & & & & $22 \%$ & $78 \%$ \\
\hline $\begin{array}{l}\text { ITL provided opportunities to practice or discuss teaching } \\
\text { concepts and techniques introduced in the course. }\end{array}$ & & & $4 \%$ & $26 \%$ & $70 \%$ \\
\hline $\begin{array}{l}\text { ITL provided me with a broader perspective on how students } \\
\text { learn and factors that may hinder learning. }\end{array}$ & & & & $25 \%$ & $75 \%$ \\
\hline $\begin{array}{l}\text { I have discussed what I learned in ITL with faculty colleagues } \\
\text { who have not yet attended. }\end{array}$ & $11 \%$ & & $9 \%$ & $32 \%$ & $49 \%$ \\
\hline $\begin{array}{l}\text { I learned contemporary assessment methods for evaluating } \\
\text { student learning (e.g., written tests, clinical assessment, } \\
\text { case-based examinations). }\end{array}$ & $1 \%$ & & $2 \%$ & $36 \%$ & $61 \%$ \\
\hline $\begin{array}{l}\text { ITL helped me develop strategies for building an academic } \\
\text { career. }\end{array}$ & $1 \%$ & $4 \%$ & $5 \%$ & $38 \%$ & $51 \%$ \\
\hline $\begin{array}{l}\text { I learned strategies to become a more effective contributor to } \\
\text { my department. }\end{array}$ & $8 \%$ & & $3 \%$ & $34 \%$ & $55 \%$ \\
\hline
\end{tabular}

Note: Percentages may not total $100 \%$ because of rounding.

and least valuable experiences in the program, their recommendations for improvement, and additional suggestions or comments. Qualitative analysis of this narrative input utilized the framework developed by Miles and Huberman ${ }^{25}$ and the National Science Foundation $^{26}$ to reduce and display survey data as well as draw and verify conclusions. Responses to the open-ended questions were analyzed for common themes and grouped accordingly. Three such independent reviews within AAL were compared to each other to produce the summary tables that appear in the report.

Participants' perceptions of the "most valuable experiences" in the program are indicated in Table 9. In a program created to introduce participants to contemporary learning theories and educational techniques, it is not surprising that instructional techniques were so often named by respondents. However, the fact that over half of participants listed networking with their colleagues and program instructors as among their most valuable experiences points out the importance of face-to-face educational opportunities and reinforces findings from the BEME and other studies of optimal design for faculty development initiatives. ${ }^{6,7}$

Only twenty-two individuals specifically identified "least valuable experiences" during the program (Table 10). A total of forty-seven other ADEA/AAL ITL Scholars responded to the question about least valuable experiences, but only to note that they perceived all experiences in the program to be valuable in some way. Thus, the percentages in Table 10 are 
Table 7. Overall assessment of the ADEA/AAL ITL by 2006-08 participants, by percentage of total respondents

Overall Assessment

Percentage

Highly positive

Positive

Negative

Highly negative
Table 8. Membership and participation in ADEA, by percentage of total respondents

\begin{tabular}{lcc} 
& Yes & No \\
\hline Current ADEA member? & $76 \%$ & $24 \%$ \\
Participated in ADEA activities in past & $33 \%$ & $67 \%$ \\
12 months? & &
\end{tabular}

comments under thematic categories, an effort was made to preserve the distinct areas of further training and experience desired, so that future programs could target these needs. The most-often cited needs were those that have long merited teachers' attention: preparation and presentation of lectures and evaluation of students' performance.

The final survey question gave participants an opportunity to provide additional comments about their experience. Forty participants took advantage of this; Appendix 1 presents a representative sample of replies including enhancement suggestions proposed by respondents. (Appendix 2 presents a list of dental schools that have sent faculty members to the program.)

Table 9. Most valuable experiences of participation, by percentage of total respondents

University politics and preparation for working with colleagues $\quad 4 \%$

Note: Participants were allowed multiple (up to three) responses.

\section{Table 10. Least valuable experiences of participation, by percentage of total respondents to this question}

Note: Participants were allowed multiple (up to three) responses. 
Table 11. Further training and experience identified by ADEA/AAL ITL Scholars as needed to improve their teaching, by percentage of total respondents

Training and Experience

Percentage

Development and delivery of lectures
$13 \%$
$13 \%$
$12 \%$
$10 \%$
$10 \%$
$8 \%$
$8 \%$
$8 \%$
$6 \%$
$6 \%$
$6 \%$

Clinical and didactic test construction and student evaluation

Face-to-face teaching experience in classroom

Learning psychology

Case-based models of teaching and learning

Teaching methodology

ITL curriculum refresher

Using digital media in teaching

Interpersonal communication

Working with faculty peers

Giving feedback to students and colleagues

\section{Discussion}

Faculty development has two foci: 1) initiatives that target individual faculty members and help these individuals address personal needs and goals for work satisfaction, effective performance, and career enhancement; and 2) initiatives that focus on institutional priorities and missions including attracting and sustaining a quality workforce and cultivating a vital academic environment that can evolve over time..$^{27-29}$ The ADEA/AAL Institute for Teaching and Learning is intended to address both aspects of faculty development. One mission is to prepare dentists and dental educators for successful academic careers. The program is designed to facilitate job satisfaction and professional growth in the academic environment with particular emphasis on helping participants acquire or refine teaching skills that will enhance interactions among teachers and students. As such, the program provides a forum for personal exploration of dental education along a continuum that includes: assessment of job fit (are teaching and the academic environment right for me?); analyzing teaching philosophy; practicing core skills in the teacher's toolbox; and clarifying career expectations and priorities.

At a broader, institutional level, provision of faculty development has historically been perceived as an essential ingredient for introduction of curriculum innovation in health professions education and for cultivating and sustaining an academic environment that supports scholarship. ${ }^{7,29,30}$ Analyses of the outcomes of efforts to revise curricula in health professions education have found that the availability and format of faculty development are predictors of the success or failure of reform initiatives. . $29,31-34^{2}$ Hendricson et al. reviewed efforts to implement four goals that have been priorities on the reform agenda (depicted in Figure 3) throughout health professions education for the past thirty years: 1) create problem-centered curricula that help students build bridges connecting the basic biological sciences to patient care; 2) use the capacities of informational technology (e.g., electronic learning, E-learning) to enhance "anytime, anywhere" accessibility and provide more stimulating learning experiences; 3) implement thematically integrated curricula conducted by interdisciplinary teams; and 4) incorporate evidence-based practice into the students' process of learning and patient care in clinics. ${ }^{7}$

As noted by the Institute of Medicine report on dental education ${ }^{35}$ and DePaola and Slavkin, ${ }^{36}$ these reforms have experienced slow, piecemeal, and episodic implementation in part due to failures to provide meaningful faculty development that allows instructors to "retool" so they can adopt educational strategies consistent with the advocated reform. ${ }^{7}$ For example, Zemsky and Massy, in a study titled "Thwarted Innovation: What Happened to E-Learning and Why," investigated E-learning (applications of information technology with emphasis on web-based learning) at six universities, including the University of Texas at Austin and Michigan State University, that had made major investments in information technology. This study explored three assumptions that have driven efforts to reform higher education through application of information technology: 1) if we build it, they will come; 2) students will take to E-learning like ducks to water; and 3) E-learning will force 


\section{Proposed Dental Education Reforms}

1. Review the curriculum in relation to the entry-level competencies needed by general dental practitioners to eliminate outdated and peripheral material.

2. Emphasize application of the basic sciences to patient care by problem-centered learning and other integrative and active-learning methods that help students understand why they are learning this material and how it can be useful.

3. Expose students to patients and the clinical environment from the first week of the curriculum to the last week.

4. Increase emphasis on evidence-based dental practice and the processes of critical appraisal of evidence to instill a culture that values the process of scientific inquiry.

5. Organize group practice teams in the clinic to promote continuity in faculty-student interaction, and coordinate patient care and students' educational experiences.

6. Arrange for all students to receive several continuous weeks of experience providing patient care in community clinics coupled with service-learning activities such as reflection exercises, analyses of the community's health care resources and needs, and interviews with health care providers and patients in the community to create a true educational experience.

7. Arrange for senior students to provide comprehensive care for at least a semester in a general dentistry model.

8. Use the capacities of information technology to enrich and diversify students' learning experiences.

9. Organize clinical education so that patients' needs come first and students do not see patients as means to an end.

10. Eliminate the smokestack (silo) curriculum model by increasing coordination and collaboration among departments/disciplines and providing interdisciplinary teaching.

11. Implement evaluation methods for nonclinical courses that focus on students' ability to use biomedical knowledge to solve problems and measure students' capacity to explain the pathophysiology of systemic and oral diseases.

12. Focus clinical evaluation methods on students' overall performance during patient care, including assessment of patient needs, diagnosis, treatment planning, and professionalism, and not just technical skills.

13. Increase educational collaboration between dentistry and other health professions and emphasize the interaction of dental and medical problems.

Source: Hendricson WD, Anderson E, Andrieu SC, Chadwick DG, Chmar JE, Cole JR, et al. Does faculty development enhance teaching effectiveness? J Dent Educ 2007;71(12):1513-33.

Figure 3. Commonly proposed curriculum modifications for predoctoral dental education

a change in the way we teach. Zemsky and Massy found that all three assumptions were not true and concluded, "E-learning will only become pervasive when faculty change how they teach - not before." ${ }^{37}$ In a study of the dental school curriculum structure and innovations by Kassebaum et al., 88 percent of academic affairs deans at U.S. and Canadian dental schools identified "faculty development related to curriculum, evaluation, and assessment" as the most important resource needed to support desired future reforms and sustain educational changes already in place. ${ }^{38}$

As shown in Figure 1, which depicts the ADEA Faculty Development Continuum, the ADEA/AAL ITL is designed to support institutional efforts to attract and cultivate a faculty workforce that has the skills and dispositions to incorporate new instructional and assessment strategies into educational ac- 
tivities. The curriculum places substantial emphasis on exposing participants to the educational reform agenda shown in Figure 3 (and discussing the merits of these proposals), as well as to new educational techniques and controversies in dental education. For example, Scholars review and discuss key articles in the recent dental education literature, including selected articles in the Perspectives and Reflections in Dental Education Series published in the Journal of Dental Education from 2006 to $2009 .{ }^{39}$

The findings of the follow-up evaluation indicate that the vast majority of respondents, including current and prospective future dental school faculty members, found the program to be a valuable experience. The written comments provided by alumni (Appendix 1) reveal their enthusiasm for this professional development program. Alumni noted that exchanging ideas, teaching experiences, and lessons learned with colleagues and program instructors were major benefits of the program.

Beginning in 2009, AAL will conduct a single program annually so that all ADEA/AAL ITL Scholars and instructors can meet at one location to facilitate enhanced networking and allow opportunity for breakout tracks to address special interests and career goals. In future years, the program will include more online learning as a component of its between-phases curriculum, and AAL also will take advantage of web-technology to create social networking venues for program alumni to encourage additional learning and information exchange. AAL also plans to release a series of Teaching Tips newsletters to alumni to provide brief, practical ideas - from clinical coaching to giving feedback - to support continued development of their teaching skills.

\section{Conclusion}

Overall, the responses of the 2006-2008 participants in the ADEA/AAL ITL suggest that this faculty development program is making progress toward achievement of its goals, especially in the areas of developing faculty who are relatively new to dental school and promoting dental education for potential new faculty members. Respondents indicated that the program has enhanced their academic skills and facilitated academic career planning. Data obtained from the follow-up evaluation indicate that this program may also provide a pathway for engaging its participants in future ADEA activities.
The high percentage of respondents who reported communications with colleagues about the program and described the sharing of insights and techniques learned during it with other faculty members at their home institution suggests that the program may have the capacity to stimulate dialogue within dental academia about new educational perspectives and innovations to address the challenges of classroom and clinical teaching. Of course, future assessments are needed to determine if these effects can be sustained longitudinally and to obtain measurements pertinent to Kirkpatrick's levels 3 and 4 regarding documentation of behavioral change and impact on institutional outcomes.

\section{Acknowledgments}

The Academy for Academic Leadership would like to recognize the outstanding support provided by the faculty and staff at the University of Missouri-Kansas City (UMKC) School of Dentistry and the University of North Carolina at Chapel Hill (UNC-CH) School of Dentistry during implementation of the programs. In particular, we recognize the outstanding contributions of Ms. Karen Wilson, Director of Continuing Dental Education at the UMKC School of Dentistry; Dr. Cynthia C. Gadbury-Amyot and Dr. Pamela R. Overman, UMKC faculty members who have served as instructors; and Ms. Sue C. Felton, Director of Continuing Dental Education and AHEC at the UNC-CH School of Dentistry.

\section{REFERENCES}

1. Chmar JE, Weaver RG, Valachovic RW. Dental school vacant budgeted faculty positions, academic years 2005-06 and 2006-07. J Dent Educ 2008;72(3):370-85.

2. Wilkerson L, Irby DM. Strategies for improving teaching practices: a comprehensive approach to faculty development. Acad Med 1998;73(4):387-96.

3. Bland CJ, Schmitz CC, Stritter FT, Henry RC, Alusie JJ. Successful faculty in academic medicine: essential skills and how to acquire them. New York: Springer Publishing Company, 1990.

4. O'Neill PN, Taylor CD. Responding to the need for faculty development: a survey of U.S. and Canadian dental schools. J Dent Educ 2001;65(8):768-76.

5. Ullian JA, Stritter FT. Types of faculty development programs. Fam Med 1997;29:237-41.

6. Steinart Y, Mann K, Centeno A, Dolmans D, Spencer J, Gelula M, Prideaux D. A systematic review of faculty development initiatives designed to improve teaching effectiveness in medical education: BEME guide no. 8 . Med Teacher 2006;28(6):497-526. 
7. Hendricson WD, Anderson E, Andrieu SC, Chadwick DG, Cole JR, George MC, et al. Does faculty development enhance teaching effectiveness? J Dent Educ 2007;71(12):1513-33.

8. Bland CJ, Seaquist E, Pacala JT, Center B, Finstad D. One school's strategy to assess and improve the vitality of its faculty. Acad Med 2002;77(5):368-76.

9. Pololi L, Clay MC, Lipkin M Jr, Hewson M, Kaplan C, Frankel RM. Reflections on integrating theories of adult education into a medical school faculty development course. Med Teacher 2001;23(3):276-83.

10. Gruppen L, Simpson D, Searle N, Robins L, Irby D. Medical education fellowships: common themes and overarching issues. Acad Med 2006;81(11):990-4.

11. Farmer EA. Faculty development for problem-based learning. Eur J Dent Educ 2004;8:59-66.

12. Dalrymple KR, Wuenschell C, Shuler CF. Development and implementation of a comprehensive faculty development program in PBL core skills. J Dent Educ 2006;70(9):948-55.

13. Dalrymple KR, Wuenschell C, Rosenblum A, Paine M, Crowe D, von Bergmann HC, et al. PBL core skills faculty development workshop: an experiential exercise with the PBL process. J Dent Educ 2007;71(2):249-59.

14. Trotman CA, Haden NK, Hendricson W. Does the dental school work environment promote successful academic careers? J Dent Educ 2007;71(6):713-25.

15. Bertolami CN. Creating the dental school faculty of the future: a guide for the perplexed. J Dent Educ 2007;71(10):1267-80.

16. Hewson MG, Copeland HL. What's the use of faculty development? Program evaluation using retrospective self-assessments and independent performance ratings. Teach Learn Med 2001;13:153-61.

17. Irby D. Teaching and learning in ambulatory care settings: thematic review of the literature. Acad Med 1995;70(10):898-931.

18. Heidenreich C, Lye P, Simpson D, Lourich M. The search for effective and efficient ambulatory teaching methods through the literature. Pediatrics 2000;105(1):231-7.

19. Chambers DW, Geissberger M, Leknius C. Association amongst factors thought to be important by instructors in dental education and perceived effectiveness of these instructors by students. Eur J Dent Educ 2004;8:147-51.

20. Henzi D, Davis E, Jasinevicius R, Hendricson W. North American dental students' perspectives about their clinical education. J Dent Educ 2006;70(4):361-77.

21. Hendricson WD, Andrieu SC, Chadwick GD, Chmar JE, Cole JR, George MC, et al. Educational strategies associated with development of problem-solving, critical thinking, and self-directed learning. J Dent Educ 2006;70(9):925-36.

22. Hand JS. Identification of competencies for effective dental faculty. J Dent Educ 2006;70(9):937-47.
23. Albino JEN, Young SK, Neumann LM, Kramer GA, Andrieu SC, Henson L, et al. Assessing dental students' competence: best practice recommendations in the performance assessment literature and investigation of current practices in predoctoral dental education. J Dent Educ 2008;72(12):1405-35.

24. Kirkpatrick DL. Evaluating training programs: the four levels. San Francisco: Berrett-Koehler Publishers, 1997.

25. Miles MB, Huberman M. Qualitative data analysis: an expanded sourcebook. Thousand Oaks, CA: Sage Publications, Inc., 1994.

26. Division of Research, Evaluation, and Communication. User-friendly handbook for mixed method evaluations. Arlington, VA: National Science Foundation, 1997.

27. Centra JA. Types of faculty development programs. J Higher Educ 1978;49:151-62.

28. Bligh J. Faculty development. Med Educ 2005;39(20): $120-2$.

29. Irby DM. Faculty development and academic vitality. Acad Med 1993;68:769-73.

30. Licari FW. Faculty development to support curriculum change and ensure the future vitality of dental education. J Dent Educ 2007;71(12):1509-12.

31. Mennin SP, Krackov SK. Reflections on relevance, resistance, and reform in medical education. Acad Med 1998;73(9 Suppl):S60-S64.

32. Bland C, Starnaman S, Wersal L, Moorhead-Rosenberg L, Zonia S, Henry R. Curricular change in medical schools: how to succeed. Acad Med 2000;75:575-94.

33. Taylor R, Reeves B, Ewings P, Binns S, Keast J, Mears R. A systematic review of the effectiveness of critical appraisal skills training for clinicians. Med Educ 2000;34:120-5.

34. Coormarasamy A, Khan KS. What is the evidence that postgraduate teaching in evidence-based medicine changes anything? A systematic review. Br Med J 2004;329(October 23):1017-22.

35. Field MJ, ed. Dental education at the crossroads: challenges and change. An Institute of Medicine Report. Washington, DC: National Academy Press, 1995.

36. DePaola DP, Slavkin HC. Reforming dental health profession education: a white paper. J Dent Educ 2004;68(11):1139-50.

37. Zemsky R, Massy WF. Thwarted innovation: what happened to e-learning and why. A final report for the WeatherStation Project. West Chester, PA: Learning Alliance for Higher Education, University of Pennsylvania, 2004. At: www.irhe.upenn.edu/WeatherStation.html. Accessed: October 17, 2007.

38. Kassebaum DK, Hendricson WD, Taft T, Haden NK. The dental curriculum at North American dental institutions in 2002-03: a survey of current structure, recent innovations, and planned changes. J Dent Educ 2004;68(9):914-31.

39. Hendricson WD. The ADEA CCI series of articles: perspectives and reflections in dental education. J Dent Educ 2009;73(2):160-5. 


\section{APPENDIX 1}

\section{Representative Comments from Respondents' Replies to Request for Additional Comments in the ADEA/AAL ITL Scholars Follow-Up Evaluation}

- This program should be mandatory for all faculty at all dental schools. It is a resource that I will continually utilize and share with my colleagues and students.

- ITL is a great experience for anyone who is thinking of teaching and doesn't feel like they are a teacher. It can make you very effective as a teacher in the clinic and classroom.

- The program is extremely valuable to anyone teaching presently or to anyone contemplating a career in dental education.

- This experience was better than I ever expected.

- It was a career-changing opportunity.

- Overall a wonderful experience. It made my transition into full-time academics from full-time private practice smoother.

- An exceptional chance to learn many aspects of academia.

- Since I attended the course, I have daily referred to concepts I learned. The course has really enhanced my confidence and ability to teach!

- The information presented strengthened foundational principals of pedagogy and has had a positive impact on my career. Based on materials and information shared, I have introduced two new courses in the college curriculum for dental students. Student course ratings have improved as well.

- It was the best educational experience I have had in my 47 1/2 years of clinical practice.

- My ITL experience was very beneficial to me intellectually and professionally. My experience allowed me to take stock of my life and what I want to do with the rest of my life.

- I feel that my academic life was divided into two sections: the before and after ITL. I feel that I was teaching by intuition before, and now I can understand the process and students' reactions (and mine) much more. I feel that my teaching is evidence-based now.

- The ITL faculty were fabulous and really, really know their stuff. It is clear that they are dedicated to helping dental faculty members improve their teaching skills.

\section{Suggestions:}

- [I need] some more learning material on how to interact diplomatically in an academic setting. Academics is more politics than I imagined.

- Let me know if you ever devise an advanced program for ITL grads.

- I think some avenue should be available to those interested in contributing ideas relative to the fundamental construction of dental school education.

- A newsletter with updates on current concepts and research in dental education would be nice.

- I am in favor of a reunion at ADEA meetings as a way to keep in touch with ITL instructors and classmates.

- Discuss how and what to plan in order to achieve tenure at a university.

- I feel like continuing education with similar topics and more detail would be helpful on a regular basis. 


\section{APPENDIX 2}

\section{Home Institutions of ADEA/AAL Institute for Teaching and Learning Scholars, 2006-09}

Albert Einstein Medical Center

Baylor College of Dentistry

Boston University Henry M. Goldman School of Dental Medicine

Creighton University School of Dentistry

Howard University College of Dentistry

Indiana University School of Dentistry

King Faisal University

Loma Linda University School of Dentistry

Louisiana State University School of Dentistry

Loyola University

Marquette University School of Dentistry

The Maurice H. Kornberg School of Dentistry,

Temple University

Medical College of Georgia School of Dentistry

Medical University of South Carolina College of Dental Medicine

Meharry Medical College School of Dentistry

New York University College of Dentistry

The Ohio State University College of Dentistry

Tufts University School of Dental Medicine

University of Alberta Department of Dentistry

University of Colorado Denver School of Dental Medicine

University of Connecticut School of Dental Medicine

University of Illinois at Chicago College of Dentistry

University of Kentucky College of Dentistry

University of Maryland Baltimore College of Dental Surgery
University of Medicine and Dentistry of New Jersey

University of Michigan School of Dentistry

University of Minnesota School of Dentistry

University of Missouri-Kansas City School of Dentistry

University of Nebraska Medical Center College of Dentistry

University of Nevada, Las Vegas, School of Dental Medicine

University of New Mexico School of Medicine

University of North Carolina at Chapel Hill School of Dentistry

University of Oklahoma College of Dentistry

University of the Pacific Arthur A. Dugoni School of Dentistry

University of Pittsburgh School of Dental Medicine

University of Puerto Rico School of Dental Medicine

University of Southern California School of Dentistry

University of Texas Health Science Center at San Antonio Dental School

University of Texas Health Science Center at Houston Dental Branch

University of Toronto Faculty of Dentistry

University of Washington School of Dentistry

Virginia Commonwealth University School of Dentistry

West Virginia University School of Dentistry 